Arab Univ. J. Agric. Sci., Ain Shams Univ., Cairo, 13(2), 187 - 196, 2005

\title{
MONITORING OF PESTICIDE RESIDUES IN RIVER NILE WATER FROM EGYPT BY SOLID-PHASE EXTRACTION FOLLOWED BY GAS CHROMATOGRAPHY AND GAS CHROMATOGRAPHY-MASS SPECTROSCOPY
}

\section{[10]}

\author{
Ali, Hanaa ${ }^{1}$, F.M.; M.A. Osman ${ }^{1}$; T.L. Potter ${ }^{2}$ and M.A. Mohamed ${ }^{1}$
}

\begin{abstract}
Solid-phase extraction (SPE), gas chromatography electron capture detector (GC-ECD) and gas chromatography nitrogen-phosphorous detector (GC-NPD) and gas chromatography-mass spectroscopy (GC-MS) were applied for trace-level determination of 20 pesticides in river nile water. Samples were collected from March to October 2003 from different sites located in Greater Cairo, Egypt. First, extraction by on-site solid-phase extraction of 1 liter from field and laboratory spiked and unspiked (raw river water) samples using poly-divinyl benzene-N-vinyl pyrolidine cartridge based sorbent. Next, water extracts were subject of analysis by GC-ECD and GC-NPD. Next, selected samples that were positive to GC-ECD or GC-NPD were analyzed by GC-MS in order to improve the determination of detected pesticides. Recoveries from laboratoy spiked samples were $>85 \%$ for 16 of the 20 compounds with \% relative standard deviation (\% RSD) in the 5 to $10 \%$ range. The lowest recoveries were for aldrin, $52 \%$ and prothiofos, $48 \%$. A similar trend was observed with p,p-DDE and p,p-DDT values. Field spike results also indicated high $\%$ recovery for most of the target compounds. Values were $>85 \%$ for 12 of the 20 analytes, as was the case in laboratory spikes, Aldrin, $54 \%$ and prothiofos, $55 \%$ yielded the lowest values. Overall field spike recovery reproducibility was lower since \% RSDs were higher, 15-40\%. Overall results indicated a relatively high degree of accuracy and precision could be achieved for most of the target compounds by methods applied in present study.
\end{abstract}

Key words: Solid-phase extraction, Pesticides residues, Gas chromatography, Mass spectroscopy

\section{INTRODUCTION}

The river Nile has been regarded as the life artery of Egypt throughout known Egyptian history. The river has a dominating influence on the economy, culture, and public health. The Nile is the sole source of drinking water for more than 16 million residents of Greater Cairo. Data documenting the levels of pesticide residues in the Nile are needed to assess the water quality. The conduct of such as-

1- Biochemistry Department, Agriculture Faculty, Cairo University, Giza, Egypt

2- USDA, Agricultural Research Service, Tifton, GA, USA 
sessments is consistent with guidelines specified in the most recent version of the FAO international code of conduct on the distribution and use of pesticides (FAO, 2003). These assessments typically include estimates of how much of pesticide active ingredient under a given set of use conditions may reach lakes, streams and rivers used for water supplies (USGS, 1999). A limiting factor in the collection of data to conduct residue analysis studies on the Nile is the need for highly specialized instrumentation to achieve appropriate detection limits. This type of equipments is costly and difficult to maintain and is not readily available in all laboratories in Egypt and other countries. A solution is to collect and extract samples in the field and ship extracts to central laboratories to maintain state-of-the-art residue analysis. One way of doing this is through the use of field-based solid-phase extraction techniques (SPE). A number of studies have shown that SPE is low cost and effective way of concentrating and preserving water samples for pesticide residues analysis (Senseman et al 1993; Johnson et al 1994; Senseman et al 1995; Ferrer and Barcelo, 1997; Aguilar et al 1999; Sabik and Jeannot, 2000; Rodriguez-Mozaz, S. et al 2004 and Gonçalves and Alpendurada, 2004). A critical quality assurance step in using SPE for pesticide extraction is determining the efficiency of recovery of analytes of interest (Ferrer and Barcelo, 1999). The need for this is based on the fact that the physical and chemical properties of pesticides and adsorbents used in SPE devices vary widely, therefore, development of a universal SPE adsorbent which will quantitatively recover all pesticides from water is an often stated research goal, but development of such universal devices remains elusive (Pichon, 2000; Sabik et al 2000 and Huck and Bonn, 2000).

The main objectives of present study are to assess the performance of a SPE cartridge which contains a new macroporous adsorbent, prepared from a co-polymer, poly-divinyl benzene-Nvinyl pyrolidone as a universal SPE adsorbent for on-site extraction of water samples through preparation and analysis of matrix spikes under field and laboratory conditions and also to determine of levels of selected pesticide residues in raw water in Greater Cairo, Egypt.

\section{MATERIAL AND METHODS}

\subsection{Chemicals}

Pesticide stock solutions of $1000 \mathrm{ppm}$ were obtained from Supelco (Milford, USA). Chromatographic grade of Methanol and Dichloromethane was obtained from Merck (Darmstadt, Germany).

\subsection{Sampling}

From March to October, 2003, 40 river Nile water samples were collected from 4 different sites around Greater Cairo (Abo Elnomrs, Tahma, Shbermant and El-Ayat). The samples were collected using 10-L glass containers. The samples were filtrated to remove suspended particles, then were split into two equal volumes.

\subsection{Spiking of samples}

One liter of sample was spiked with aliquots of pesticide mixtures. This included a 3 component mixture of triazine herbicides (atrazine, prometon and 
ametryn, and a 6 components mixture of organophosphate insecticides (ethoprophos, disulfoton, methyl parathion, fenchlorphos, chlorpyrifos and prothifos and an 11 component mixture of chlorinated hydrocarbon insecticides (aldrin, gamma-BHC (lindan), $p, p$-DDD, $p, p$ DDE, $p, p$-DDT, dieldrin, endosulfan I, endosulfan II, endosulfan sulfate, endrin and heptachlor.The target spiking level for each component was $1 \mu \mathrm{g} / \mathrm{L}^{-1}$.

\subsection{SPE extractions}

Automated SPE was performed with a Supelco manifold extraction unit connected with an oil-less vacuum pump. The cartridges (OASIS HLB $6 \mathrm{ml}, 200$ mg, Waters, Milford, USA) were conditioned sequentially with $3 \mathrm{ml}$ of methanol and $3 \mathrm{ml}$ of deionized water. One liter of water sample was passed though the cartridge at a flow-rate of $5 \mathrm{ml} / \mathrm{min}$ and then washed with $5 \mathrm{ml}$ of deionized water. After extraction, all cartridges were attached for $30 \mathrm{~min}$ to a Supelco evaporating unit connected with purified nitrogen gas to eliminate water residues from cartridges. Dried cartridges were wrapped in aluminum foil and shipped to the Southeast Watershed Research Laboratory located in Tifton, GA, USA. Shipments were made using the an express mail service which provided delivery within 3-5 days without freezepacks or other material designed to keep cartridges cold. Immediately after receipt in the USA, the cartridges were sequentially eluted with pesticide residue analysis certified methanol and methylene chloride. The combined eluent volume was reduced to approximately $1 \mathrm{ml}$ by evaporation under a stream of purified nitrogen gas. An additional $10 \mathrm{ml}$ of methanol was added and the entire sample concentrated to $1.00 \pm$
0.01 g. After transfer to a glass autosampler vial, the sample was fortified with $5 \mu \mathrm{g}$ of 2-chlorolepine (as an internal standard) and stored in a $-20{ }^{\circ} \mathrm{C}$ freezer until analysis.

\subsection{GC and GC-MS conditions}

Gas chromatography was carried out with thermoionic ionization (HP model 6890), an electron capture detector (HP model 5890) and a GC-MS (HP model 5972) was used. The instruments utilized helium as a carrier gas under the following conditions: fused-silica column HP-5 MS (30 m x $\left.0.25 \mathrm{~mm}, \mathrm{~d}_{\mathrm{f}}-0.25 \mu \mathrm{m}\right)$, $60^{\circ} \mathrm{C}$ for $1 \mathrm{~min}, 60-175^{\circ} \mathrm{C}(4 \mathrm{~min})$ at $6^{\circ} \mathrm{C} / \mathrm{min}, 175-240^{\circ} \mathrm{C}(5 \mathrm{~min})$ at $3^{\circ} \mathrm{C} / \mathrm{min}$, $240-300^{\circ} \mathrm{C}(1 \mathrm{~min})$ at $7^{\circ} \mathrm{C} / \mathrm{min}$, split-less, temperature of interface was at $270^{\circ} \mathrm{C}$, source temperature at $200^{\circ} \mathrm{C}$, temperature of injector at $250^{\circ} \mathrm{C}$. Electron impact ionization at $70 \mathrm{eV}$ was used. All samples were analyzed in the SIM mode for quantitative analysis of the compounds (Major ions corresponding to the typical fragments of the compounds were selected, and the scan mode was set in the range $70-450 \mathrm{u}$ for confirmation of the spectral data against a real standard and library search.

\section{RESULTS AND DISCUSSION}

Summary statistics for percent recovery of 20 compounds from field and laboratory spikes are compiled in Tables (1 and 2). When computing field spike recovery, the response (if any) obtained for each compound in the unspiked portion of each sample was subtracted from responses obtained in corresponding spiked portions. The adjusted value was compared to the target $1 \mu \mathrm{g} \mathrm{L} \mathrm{L}^{-1}$ nominal spiking rate. 
Table 1. Recovery of selected pesticides in selected SPE cartridges after spiking at $1 \mu \mathrm{g}$ $\mathrm{L}^{-1}$ in distilled deionized water $(\mathrm{n}=5)$

\begin{tabular}{|lllll|}
\hline Compound & Class & $\begin{array}{c}\text { Instrumental } \\
\text { analysis } \\
\text { mode }\end{array}$ & $\begin{array}{c}\text { Average } \\
\% \mathrm{R}\end{array}$ & $\begin{array}{c}\text { Standard } \\
\text { deviation }\end{array}$ \\
\hline ametryn & triazine & GC-NPD & 100 & 3.9 \\
atrazine & triazine & GC-NPD & 110 & 4.8 \\
prometon & triazine & GC-NPD & 110 & 2.2 \\
chloropyrifos & organophosphate & GC-NPD & 88 & 2.8 \\
disulfoton & organophosphate & GC-NPD & 94 & 3.8 \\
ethoprophos & organophosphate & GC-NPD & 106 & 5.0 \\
fenchlorphos & organophosphate & GC-NPD & 91 & 2.4 \\
methyl parathion & organophosphate & GC-NPD & 87 & 17 \\
prothiofos & organophosphate & GC-NPD & 48 & 4.5 \\
aldrin & chlorinated hydrocarbon & GC-ECD & 52 & 2.7 \\
p,p-DDD & chlorinated hydrocarbon & GC-ECD & 90 & 11 \\
p,p-DDE & chlorinated hydrocarbon & GC-ECD & 69 & 3.7 \\
p,p-DDT & chlorinated hydrocarbon & GC-ECD & 76 & 0.9 \\
dieldrin & chlorinated hydrocarbon & GC-ECD & 100 & 4.7 \\
endosulfan I & chlorinated hydrocarbon & GC-ECD & 110 & 2.1 \\
endosulfan II & chlorinated hydrocarbon & GC-ECD & 110 & 9.9 \\
endosulfan sulfate & chlorinated hydrocarbon & GC-ECD & 110 & 7.9 \\
endrin & chlorinated hydrocarbon & GC-ECD & 110 & 4.1 \\
heptachlor & chlorinated hydrocarbon & GC-ECD & 86 & 4.7 \\
lindane (BHC isomer) & chlorinated hydrocarbon & GC-ECD & 110 & 2.9 \\
\hline & & & & \\
\hline
\end{tabular}

$\% \mathrm{R}: \%$ recovery 
Table 2. Recovery of selected pesticides on SPE cartridges after spiking at $1 \mu \mathrm{g} \mathrm{L}^{-1}$ in distilled deionized water $(n=5)$

\begin{tabular}{|c|c|c|c|c|c|}
\hline \multirow[b]{2}{*}{ Compound } & \multicolumn{3}{|c|}{ Number of results classed as outliers } & \multicolumn{2}{|c|}{$\%$ Recovery } \\
\hline & $\begin{array}{c}\text { total } \\
10 \%<\% \mathrm{R}<130 \%\end{array}$ & $\begin{aligned} & \text { high } \\
> & 130 \%\end{aligned}$ & $\begin{array}{l}\text { low } \\
<10 \%\end{array}$ & average & SD \\
\hline ametryn & 5 & 0 & 5 & 80 & 14 \\
\hline atrazine & 30 & 25 & 5 & 96 & 26 \\
\hline prometon & 5 & 0 & 5 & 93 & 19 \\
\hline prometryn & 30 & 5 & 25 & 81 & 36 \\
\hline chloropyrifos & 35 & 25 & 10 & 80 & 29 \\
\hline dichlorvos & 15 & 15 & 0 & 64 & 25 \\
\hline disulfoton & 35 & 35 & 0 & 65 & 29 \\
\hline ethoprophos & 30 & 30 & 0 & 95 & 19 \\
\hline fenchlorphos & 40 & 40 & 0 & 89 & 25 \\
\hline methyl parathion & 80 & 70 & 10 & 118 & 9 \\
\hline prothiofos & 5 & 5 & 0 & 55 & 29 \\
\hline aldrin & 45 & 0 & 45 & 54 & 30 \\
\hline dieldrin & 45 & 35 & 10 & 91 & 30 \\
\hline $\mathrm{p}, \mathrm{p}-\mathrm{DDT}$ & 55 & 0 & 55 & 64 & 29 \\
\hline $\mathrm{p}, \mathrm{p}-\mathrm{DDD}$ & 25 & 20 & 5 & 90 & 20 \\
\hline $\mathrm{p}, \mathrm{p}-\mathrm{DDE}$ & 40 & 15 & 25 & 78 & 19 \\
\hline endosulfan I & 5 & 5 & 0 & 88 & 17 \\
\hline endosulfan II & 5 & 5 & 0 & 92 & 26 \\
\hline endosulfan sulfate & 10 & 10 & 0 & 83 & 31 \\
\hline endrin & 20 & 20 & 0 & 91 & 26 \\
\hline lindane(BHC isomer) & 75 & 75 & 0 & 92 & 12 \\
\hline
\end{tabular}

$\% \mathrm{R}: \%$ recovery 
The results for unspiked samples (raw River Nile samples) are presented in Table (3). Recoveries from laboratory spiked samples were $>85 \%$ for 16 of 20 compounds with \% relative standard deviation (\% RSD) in the 5 to $10 \%$ range (Table, 1). The lowest recoveries were for aldrin, $52 \%$, and prothiofos, $48 \%$. No explanation is readily available although it is notable that the results were reproducible since the $\%$ RSD was $<5 \%$. A similar trend was observed with p,p-DDE and p,p- DDT values. Recoveries were less than quantitative, $68 \%$ and $76 \%$ respectively, but highly reproducible, \% RSD $<5 \%$. Overall results indicated a relatively high degree of accuracy and precision can be achieved for most of the target compounds by SPE extraction. For the 4 compounds which yielded recoveries that were less than quantitative, low $\%$ RSD's were observed. Field spike results also indicated a high $\%$ recovery for most of the compounds (Table, 2). Values were $>85 \%$ for 12 of 20 analytes. As was the case in the laboratory spikes, aldrin, $54 \%$ and prothiofos, $55 \%$, yielded the lowest values. Overall field spike recovery reproducibility was lower since \% RSD's were higher, $15-40 \%$. Higher \% RSDs in field versus laboratory spikes were expected and commonly observed. While field spike results appeared comparable to laboratory spike data, many field values were highly uncertain. This was indicated by the large number of outliers, i.e.samples with $\%$ recoveries $<10 \%$ or $>$ $130 \%$, observed for many compounds (Table, 2). Among the 20 samples analyzed, 19 of 20 had at least 1 result considered an outlier. Compounds stood out in this regard, the organophosphate, methyl-parathion, and the chlorinated hydrocarbon, lindane. A total $75 \%$ of lindane and $80 \%$ of methyl-parathion results were anomalously high, > 130\%. One possible explanation was the introduction of coeluting interferences during field extraction. Field blanks were unavailable for analysis. While it appears that uncertainties in \% recoveries of methyl-parathion and lindane may have been connected to coextraction and or introduction of interfering compounds, unspiked sample results argued against this. As indicated in table 3 , there were only sporadic detections of methyl-parathion and no lindane detections in any of the unspiked samples analyzed. This was the case for nearly all of the 20 used compounds. When residues were detected, levels were uniformly close to analytical limits of detection. The only exception was aldrin. It was tentatively identified in 11 samples by GC-ECD. However, an GC-MS analysis did not confirm results, it is concluded that an interference likely yielded a false positive result, however, further work is required to verify this. Among the field spike samples aldrin \% recovery results were also problematic. There were numerous outliers with low $\%$ recovery. The opposite was observed with dieldrin suggesting conversion of aldrin to dieldrin in some samples. Dieldrin is an oxidized form of aldrin. Studies have shown that UV irradiation readily catalyzes aldrindialdrin conversion (USEPA, 2000 and 2002). This could have occurred when samples, sample solvent extracts or standard spiking solution were exposed to light. Another conversion that may have occurred during analysis was the transformation of p,p- DDT and $p, p$ DDE to $p, p-D D D$. A possible point where this occurred was during gas chromatographic (GC) analysis. Dechlorination 
Table 3. Concentration of selected pesticides in Nile River nile water samples $(n=20)$

\begin{tabular}{|lccc|}
\hline Compound & \multicolumn{3}{c|}{ Concentration $\left(\mu \mathrm{g} \mathrm{L}^{-1}\right)$} \\
\cline { 2 - 4 } ametryn & $\%$ detects & minimum & maximum \\
atrazine & 0 & 0.64 & $<0.13$ \\
prometon & 0 & 0.13 & $<0.13$ \\
prometryn & 0 & $<0.13$ & $<0.13$ \\
chloropyrifos & 5 & 0.21 & $<0.06$ \\
dichlorvos & 0 & 0.13 & $<0.13$ \\
disulfoton & 0 & $<0.13$ & $<0.13$ \\
ethoprophos & 5 & 0.09 & $<0.06$ \\
fenchlorphos & 5 & 0.20 & $<0.06$ \\
methyl parathion & 5 & 0.20 & $<0.06$ \\
prothiofos & 15 & 0.49 & $<0.13$ \\
aldrin & 0 & $<0.06$ & $<0.06$ \\
p,p-DDT & 5 & 1.04 & $<0.01$ \\
p,p-DDD & 5 & 0.09 & $<0.01$ \\
p,p-DDE & 5 & $<0.01$ & $<0.01$ \\
dieldrin & 5 & 0.33 & $<0.01$ \\
endosulfan I & 5 & $<0.01$ & $<0.01$ \\
endosulfan II & 5 & 0.21 & $<0.01$ \\
endosulfan sulfate & 5.09 & $<0.01$ \\
endrin & 5 & 0.011 & $<0.01$ \\
\hline lindane(BHC isomer & 5 & 0.01 \\
\hline
\end{tabular}


of $p, p-$ DDT with formation of $p, p$ DDE and $p, p-D D D$ is often observed following $p, p-$ DDT injection into heated GC injection ports unless GC systems are carefully deactivated. Even if deactivation is maintained, the conversion can occur if field sample extracts have large amounts of co-extracted materials which are simultaneously injected with target analytes. Injection of p,p- DDT standards alone did not indicate substantial degradation and production of dechlorinated by-products, thus it was concluded that Nile samples likely contained coextracted materials which promoted $\mathrm{p}, \mathrm{p}$ DDT degradation upon injection. Overall results indicated a relatively high degree of accuracy and precision could be achieved for the most target compounds by applied methods in present study.

\section{ACKNOWLEDGEMENTS}

The authors gratefully acknowledge the funding by The National Academy of Science and Technology, Egypt and United State Department of Agriculture, USA through contract No.ENV-002-005. We also gratefully acknowledge the assistant of the Toutheast Watershed Research Laboratory located in Tifton, USA for analysis of water samples by GC and GCMS.

\section{REFERENCES}

Aguilar, C.; I. Ferrer; F. Borrull; R.M. Marce and D. Barcelo (1999). Monitoring of Pesticide in River Nile Water Based on Samples Previously Stored in Polymeric Cartridges Followed by Online-solid-phase Extraction-liquid chromatography-diode Aarray Detection and Confirmation by Atmospheric Pressure
Chemical Ionization Mass Spectroscopy. Anal. Chinica Acta. 386: 237-248.

Ferrer, I. and D. Barcelo (1997). Stability of Pesticides Stored on Polymeric Solid-phase Extraction Cartridges. J. Chromatogr. A 778: 161-170.

Ferrer, I. and D. Barcelo (1999). Validation of New Solid-phase Extraction Materials for The Selective Enrichment of Organic Contaminants from Environmental Samples. Tr. Anal. Chem. 18: 180-192.

FAO, (2003). International Code of Conduct on the Distribution and Use of Pesticides. Food and Agriculture Organization of the United Nations, Rome.

Gonçalves, C. and M.F. Alpendurada (2004). Solid-phase Micro-extraction-gas chromatography-(tandem) Mass Spectrometry as a Tool for Pesticide Residue Analysis in Water Samples at High Sensitivity and Selectivity with Confirmation Capabilities. Journal of Chromatography A, Volume 1026, Issues 1-2, 13 February 2004, Pages 239-250.

Huck, C.W. and G.K. Bonn (2000). Recent Development in Polymer-based Ssorbents for Solid-phase Extraction. $\boldsymbol{J}$. Chromatogr. A 885: 51-72.

Johnson, W.G.; T.L. Lavy and S.A. Senseman (1994). Stability of Selected Pesticides on Solid-phase Extraction Disks. J. Environ. Qual. 23: 1027-1031.

Pichon, V. (2000). Solid-phase Extraction for Multi-residue Analysis of Organic Contaminants in Water. J. Chromatogr. A 885: 195-215.

Rodriguez-Mozaz, S.; J. Maria López de Alda and B. Damià (2004). Monitoring of Estrogens, Pesticides and Bisphenol A in Natural Waters and Drinking Water Treatment Plants by Solidphase extraction-liquid-chromatographymass spectrometry. Journal of Chroma- 
tography A, Volume 1045, Issues 1-2, 6 August 2004, pp. 85-92.

Sabik, H. and R. Jeannot (2000). Stability of Organophosphorous Insecticides on Graphitized Carbon Black Extraction Cartridges Used for Large Volumes of Surface Water. J. Chromatogr. A 879: 73-82.

Sabik, H.; R. Jeannot and B. Randeau (2000). Multiresidue Methods Using Solid-phase Extraction Techniques for Monitoring Priority Pesticides, including Triazines and Degradation Products in Ground and Surface Waters. J. Chromatogr. A 885: 217-236.

Senseman, S.A.; T.L. Lavy; J.D. Mattice; B.M. Myers and B.W. Skulman (1993). Stability of Various Pesticides on Memberanous Solid-phase Extraction Media. Environ. Sci. Technol. 27: 516519.

Senseman, S.A.; T.L. Lavy; J.D. Mattice and E.E. Gbur (1995). Influence of
Dissolved Humic Acid and Camontmorillonite Clay on Pesticide Extraction Efficiency from Water Using Solid-phase Extraction Discs. Environ. Sci. Tech. 29: 2647-2653.

USEP. A, (2000). Estimating of Pesticide Concentrations in Drinking Water for FQPA Risk Assessment. pp. 1-25. Report Prepared for The Committee to Advise on Reassessment and Transition, U.S. Environmental Protection Agency, Washington, D.C.

USEPA, (2002). Health Effects Support Document for Aldrin-dieldrin. pp. 5-20. Office of Pesticides Programs, U.S. Environmental Protection Agency, Washington, D.C.

USGS, (1999). The Quality of our Nation's : Water-Nutrients and Pesticides. U.S. Geological Survey Circular 1225, pp.1-82.

C.F from www.dwatcm.wr.usgs.gov/ ccpt/pns_data/data.htm1.updated May 2004 
بحلة اتحاد الجامعات العربية للدراسات والبحوث الزراعية ، جامعة عين شمس ، القاهرة ، 13(2) ، 187 - 196 في 196 ، 2005

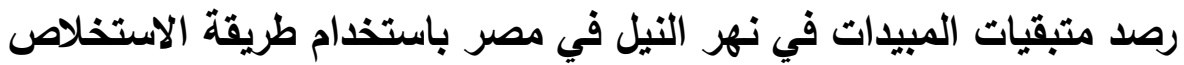
بالطور الصلب والتحليل بجهاز الكروماتوجرافي الغازي والكروماتوجرافي الغازي فئي المتصل بمطياف الكتبلة

[10]

هناء فوزي محمد علي 1 - محى الدين على عثمان 1 - توماس بوتر 2 -

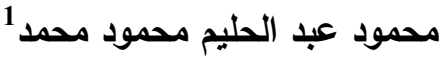

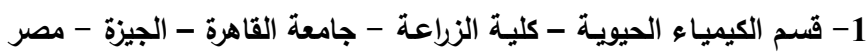

2- معمل هيئة الزراعة الأمريكية - تفتون - جورجيا - الولايات المتحدة الأمريكية

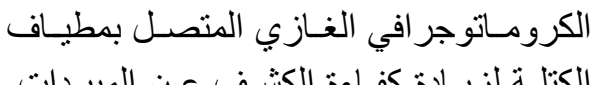

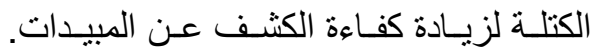

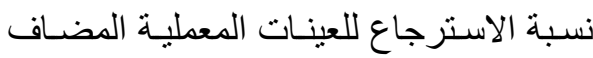

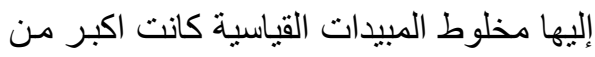

85 و و ذلك لحو الي من 16 من 20 مركب التب

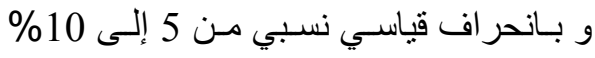

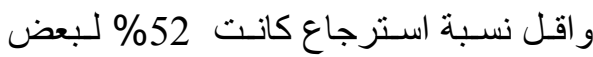

المبيدات الكلورينية و48\% لبعض المبنة المبيدات

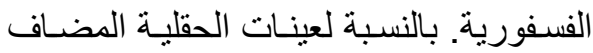

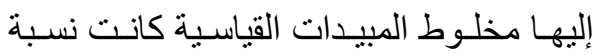

استرجاع عالية لمعظم المركبات المستهدفة و المبر

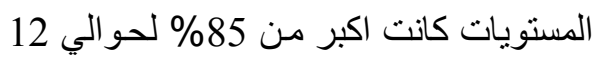
إلى 20 مركب ـ و اقل نسبة استرجاع كانت

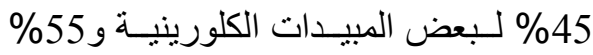
لبعض المبيـات الفسفورية. عمومـا النتـائج دلت علي انه يمكن الوصول إلى درجة عالية الفية

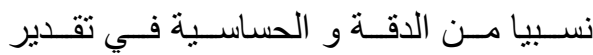

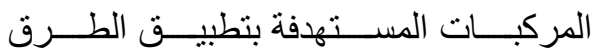
المستخدمة في هذه الدر اسة.
الاسـتخلاص بـالطور الصـلب وجهــاز

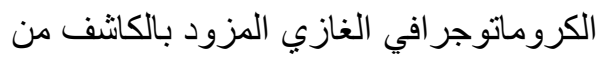

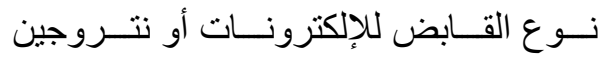

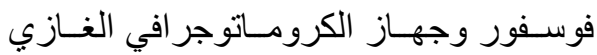

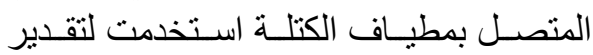

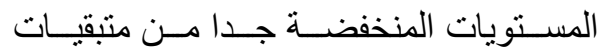

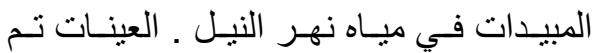

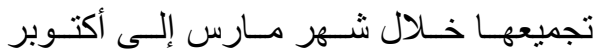
2003 مـن منــاطق مختلفـة تقع فـي القـاهرة

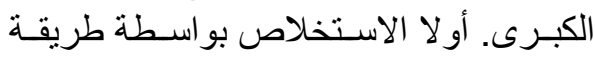

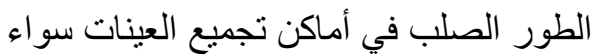

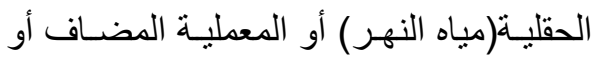

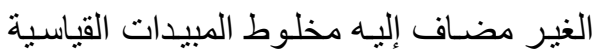
بحيث يضاف لتر من العينات إلى أعمدة من لئل

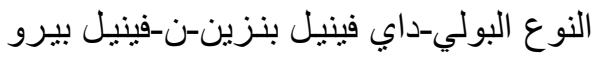

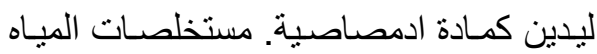

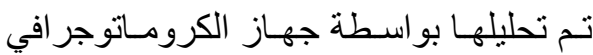

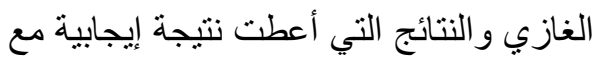

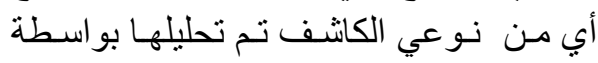
ز

$$
\text { تحكيم: أ.د راجى رياض فرنسيس أ.د محمد حلمى بـلال }
$$


Arab Univ. J. Agric. Sci., Ain Shams Univ., Cairo, 12(1), ..- .., 2004

1- Meat and Fish Technology Research Department, Food Technology Institute, Agriculture Research Center, Giza, Egypt

(Received November 12, 2003)

(Accepted December 30, 2003) 